\title{
Can R\&D alliances facilitate the formation of a cartel? The example of the European IT industry
}

Citation for published version (APA):

van Wegberg, M. J. (1995). Can R\&D alliances facilitate the formation of a cartel? The example of the European IT industry. METEOR, Maastricht University School of Business and Economics. METEOR Research Memorandum No. 004 https://doi.org/10.26481/umamet.1995004

Document status and date:

Published: 01/01/1995

DOI:

10.26481/umamet.1995004

Document Version:

Publisher's PDF, also known as Version of record

\section{Please check the document version of this publication:}

- A submitted manuscript is the version of the article upon submission and before peer-review. There can be important differences between the submitted version and the official published version of record.

People interested in the research are advised to contact the author for the final version of the publication, or visit the DOI to the publisher's website.

- The final author version and the galley proof are versions of the publication after peer review.

- The final published version features the final layout of the paper including the volume, issue and page numbers.

Link to publication

\footnotetext{
General rights rights.

- You may freely distribute the URL identifying the publication in the public portal. please follow below link for the End User Agreement:

www.umlib.nl/taverne-license

Take down policy

If you believe that this document breaches copyright please contact us at:

repository@maastrichtuniversity.nl

providing details and we will investigate your claim.
}

Copyright and moral rights for the publications made accessible in the public portal are retained by the authors and/or other copyright owners and it is a condition of accessing publications that users recognise and abide by the legal requirements associated with these

- Users may download and print one copy of any publication from the public portal for the purpose of private study or research.

- You may not further distribute the material or use it for any profit-making activity or commercial gain

If the publication is distributed under the terms of Article $25 \mathrm{fa}$ of the Dutch Copyright Act, indicated by the "Taverne" license above, 
Can R\&D Alliances Facilitate the Formation of a Cartel?

The Example of the European IT Industry

by

M. van Wegberg*

Firms may coordinate their R\&D decisions by a merger or an $R \& D$ alliance. The European Union stimulates R\&D alliances. It expects that these stimulate R\&D investments, and guarantee that the cooperating firms compete in the product market. The alliances may, however, stimulate firms to collude in the product market. Alliances then point to emerging cartels. The paper explores the conditions where this fear holds.

JEL Codes: L13, L14, L63, L86, L96

March, 1995

* Faculty of Economics and Business Administration, Rijksuniversiteit Limburg, P.O. Box 616, 6200 MD Maastricht, The Netherlands. Tel. +31 43 883654. Fax: +31 43258495. E-mail: M.vanWegberg@MW.RuLimburg.nl. A grant from the Dutch science foundation NWO supported this study. 


\section{Introduction}

The increasing numbers of $R \& D$ alliances in, for example, the European Information Technology industries show ample cases where the same firms meet each other over and over again as they conclude one alliance after the other. Alliances may facilitate the formation of (implicit) cartels among them. This paper discusses some evidence and explores this intuition by modelling the effect of alliances on product market competition in comparison with the effect of mergers..

The 1980s witnessed a growth in the number of technology alliances among European firms. This is especially striking in information technology (IT). Networks were created of private technology alliances, along-side with EC-organised (and subsidized) alliances. Hagedoorn and Schakenraad (1993) show that both networks created close links among Europe's leading IT firms. In particular twelve European leading IT firms forged ever closer links by means of cooperative R\&D links. ${ }^{1}$ These Big Twelve participated in the Round Table that ushered in the ESPRIT programme, the European Strategic Programme for Research and Development in Information Technologies. A related programme is RACE (Research and development in Advanced Communications technologies for Europe), a spin-off of ESPRIT. Including Eureka projects, Information Technologies account for 64\% (589) of the 920 joint cost-sharing technology projects listed in the Merit-Cati database over the period 1983 to 1989. Hagedoom and Schakenraad (1993) are able to demonstrate that the intensity by which a firm participates in private $R \& D$ technology links is a significant explanatory variable for its participation in the European cost-sharing programmes. That is, 'these subsidized R\&D networks are added to already existing or emerging private networks.' (op. cit., p. 387) The authors add, 'European cost-sharing programmes, as developed during the 1980s, appear to play a role in a process of gradual concentration of the

1. These were AEG, Bull, CGE, GEC, ICL, Nixdorf, Olivetti, Philips, Plessey, Siemens, STET, and Thomson (Hagedoorn and Schakenraad, 1993). 
European information technology industry towards a wide-oligopolistic structure in which only a relatively small number of large European companies play an important role.' (p. 387)

A corollary of this point of view is that alliances may facilitate the formation of a cartel. Mytelka (1995) argues that European IT firms did indeed more or less deliberately forge closer links. They were losing market share over the 1980s. To counter this, they set out to coordinate their strategies to catch up on their U.S. and Japanese rivals. Part of their strategy was to develop themselves from national champions into European firms. They also needed better access to new technology, while rethinking their product portfolios. The $R \& D$ alliances served the obvious purpose of developing much needed new technology. They also, according to Mytelka, served the additional purposes of helping to coordinate the catching up strategies. She argues that by the beginning of the 1990s the cartel unravelled. The IT firms had failed to cooperate with the potential (industrial) users of their technologies. For several European firms, their constant need to reorganize prevented a commitment to their European partnerships, witnessing the policy changes by firms such as Philips, Olivetti and Bull. Some of the Big Twelve lost their independence: AEG to Daimler Benz, Nixdorf to Siemens, Plessey to GEC Siemens, and ICL to Fujitsu. Many turned to non-European firms as sources of technology (e.g., Olivetti and Siemens).

The aim of this paper is to explore the proposition that $R \& D$ alliances aid the formation of a cartel within a game-theoretical formulation. A model compares the strategic implications of an alliance to those of a merger, which is an alternative way to coordinate $R \& D$ decisions. The guiding hypothesis is that unlike a merger, an $R \& D$ alliance may stimulate tacit collusion. The next section discusses some relevant theories. The subsequent sections develop the model. The results contain the conditions where the hypothesis holds, that a merger disrupts collusion, whereas an alliance sustains collusion. The appraisal offers a feedback to the discussion about the IT industry, and cartel formation in the European IT industry. 


\section{Literature about R\&D Alliances, Merger, and Cartels}

The object of this paper draws together three often separate fields of analysis in industrial organisation: merger, cartels, and R\&D alliances. Mergers raise an industry's level of concentration. High concentration levels may be conducive to collusion, which would explain the positive effect of concentration on profit rates. Combining these insights, industrial economists used to think that mergers would promote collusion (or tacit cartels). Davidson and Deneckere (1984) reassessed this idea. They explore a merger by $\mathrm{M}$ firms among $\mathrm{N}$ symmetrical firms in a homogeneous good Cournot oligopoly. They argue that the merger may disrupt collusion. In a non-cooperative context, firms sustain collusion by a threat to revert to competition if a firm defects from the collusion. This threat is more severe, the lower the profits firms will earn in competition. The effect of a merger is that it raises the profits in competition (by creating market power), thus reducing the threat value of a reversal to competition. The latter effect weakens the cartel, and may destroy it. If fims anticipate this, they face the choice between either merger (and thus competition, among a reduced number of firms) or collusion (by a larger number of fims). This is an important insight, that drives much of the results of this paper.

Now turn to R\&D. Firms may benefit from coordinating their R\&D choices. There are strategic reasons for this, as $\mathrm{R} \& \mathrm{D}$ may affect production costs (through process innovations), and costs in turn affect competition in the product market. Know how may leak to other firms, in other words, $R \& D$ may have positive spillovers on other firms. This provides firms with an additional motive to coordinate their R\&D decisions: to internalize these externalities. Two ways to coordinate R\&D decisions have received considerable attention in the 1980s and 1990s: merger and R\&D alliances. Consider some empirical evidence.

Chakrabarti, Hauschildt and Süverkrüp (1994) conclude from the literature that technology ranks in the middle of the strategic considerations of acquisitions (behind motives such as market dominance, market shares, and cost reduction). In a sample of 86 German-American foreign 
acquisitions in 1978-1987, they distinguish the acquirers in four groups on the basis of their motives: market-oriented entrepreneurs, short-term profit seekers, technology acquirers and preemptive market protectors. The latter two are interested in technology transfers, and are mainly located in high-tech industries. Technology plays a large part in some but not all mergers, therefore. The same holds for alliances. For example, in a Belgian database of alliances, research and development appeared the motive (or functional activity) for $20.9 \%$ of the non-Belgian alliances, and $25.3 \%$ for the Belgian alliances (i.e., alliances which include at least one Belgian firm) (Veugelers, 1993, p. 7).

In these cases, mergers and alliances are substitute sources of technology coordination. This is confirmed by Link and Bauer (1989), who found that (according to the managers involved) mergers and alliances were (on average) less important sources of technology than own R\&D but more important than licensing. Comparing the managers' views in 1982 to the ones in 1985, they also found that mergers decreased in importance as a source of technology, whereas cooperative research increased in importance.

The choice between merger and alliance depends on their salient differences. Industrial economists stress one in particular. An alliance is topical: it coordinates a particular objective or project. A merger or acquisition, instead, allows the firms to coordinate all decisions, from precompetitive decisions about R\&D to product market decisions. D'Aspremont and Jacquemin (1988) and De Bondt and Veugelers (1991) analyze the implications of this in the following setting. Two firms compete in the product market as Cournot duopolists (with heterogeneous products). They also do R\&D, which reduces their marginal costs, and thus affects their subsequent decisions about output levels. Each firm's R\&D has a positive spillover on the other firm's know how, and thus reduces its marginal cost level as well. Both firms may compete both in R\&D and, subsequently, in output levels. If they form an $\mathrm{R} \& \mathrm{D}$ alliance, they coordinate their $\mathrm{R} \& \mathrm{D}$ decisions, while competing in the product market. If they merge, they coordinate both their $R \& D$ and output decisions (a merger). D'Aspremont and Jacquemin (1988) and De Bondt and Veugelers (1991) 
show that the greater degree of coordination achieved by the merger means that it is more profitable than an alliance.

In order to understand the effects of an R\&D alliance on cartel formation we need to integrate the insights from the merger/collusion literature with the merger/R\&D alliance literature. We do so in a three-stage game. In the first stage, the firms merge or form an alliance. In the second stage, they choose $R \& D$ levels. In the third stage, given the outcomes of the previous stages, they choose output levels. The product market allows for the possibility of collusion. The next sections discuss these stages, beginning with the last one.

\section{Assumptions of the Model}

Consider three heterogeneous products $(i=1 . .3)$, with a price:

(1) $\mathrm{P}_{\mathrm{i}}=\mathrm{a}-\mathrm{q}_{\mathrm{i}}-\mathrm{bQ}_{\mathrm{i}}$,

where $\mathrm{q}_{\mathrm{i}}$ is firm i's output level, and $\mathrm{Q}_{\mathrm{i}}$ is the aggregate output level of firm i's rivals. Products are complements if $b<0$, substitutes if $b>0$, and homogeneous if $b=1$. Marginal costs are constant at $c_{i}(i=1 . .3)$. Profits per product are

(2) $\quad \pi_{\mathrm{i}}=\left(\mathrm{a}-\mathrm{c}_{\mathrm{i}}-\mathrm{q}_{\mathrm{i}}-\mathrm{b} \mathrm{Q}_{\mathrm{i}}\right) \mathrm{q}_{\mathrm{i}}$

Firms 1 and 2 may merge, hence there are either two or three firms in the market. If firms 1 and 2 merge, they create a multiproduct firm, as the merged firm continues to supply both products. To focus on the decision by firms 1 and 2 to merge or, alternatively, to form an alliance, assume that only they do R\&D. Thus fim 3 is a non-merging, non-innovating rival (for convenience).

The model is dynamic with the following time structure. At $t=0$, firms 1 and 2 decide 
about the R\&D levels. At $t=1$, they introduce their innovation. They meet firm 3 in the product market. They may either collude with firm 3 or compete. This interaction repeats itself through time from period 1 onwards (an infinite repeated game).

Collusion introduces a time element in product market competition. This is inherent in the idea of collusion by non-cooperative firms. In a non-cooperative context, each individual firm gains from unilateral defection (by increasing the output relative to the collusive output levels). Collusion can only be sustained by the threat to react to defection in the current period by a punishment in the subsequent periods. Assume for convenience that firms support collusion by a grim trigger strategy. That is, if a firm defects from the collusive output levels, $\mathrm{q}_{\mathrm{i}}{ }^{\mathrm{C}}$, the other(s) punish it in the subsequent period by returning to the Cournot equilibrium, with Cournot output levels $\mathrm{q}_{\mathrm{i}}^{\mathrm{P}}$. They stay there forever. Firms discount future revenues with an interest rate $r$. The discounted profits from collusion starting at period 1 are $\pi_{\mathrm{i}}^{\mathrm{Cn}}+\pi_{\mathrm{i}}^{\mathrm{Cn}} / \mathrm{r}$, where the superscript $\mathrm{C}$ refers to collusion and $n$ (= 2 or 3 ) refers to the number of firms. If firm $i$ cheats (defects) its colluding rivals at period 1 , it will be punished from period 2 onwards. Its discounted profits $(a t=1)$ are $\pi_{\mathrm{i}}^{\mathrm{Dn}}+\pi_{\mathrm{i}}^{\mathrm{Pn}} / \mathrm{r}$, where superscript $\mathrm{D}$ refers to cheating, and $\mathrm{P}$ to punishment (= the Cournot oligopoly). Firm $i$ will collude if and only if $\pi_{\mathrm{i}}^{\mathrm{Cn}}+\pi_{\mathrm{i}}^{\mathrm{Cn}} / \mathrm{r} \geq \pi_{\mathrm{i}}^{\mathrm{Dn}}+\pi_{\mathrm{i}}^{\mathrm{Pn}} / \mathrm{r}$, that is,

$$
\text { Collusion if } r \leq \frac{\pi_{i}^{C n}-\pi_{i}^{P n}}{\pi_{i}^{D n}-\pi_{i}^{C n}} \text {. }
$$

If equation (3) holds for all firms, the firms collude. At $t=1$, the discounted profit flow of firm $i$ thus equals $\pi_{\mathrm{i}}^{\mathrm{C}}(1+1 / \mathrm{r})$. If equation (3) fails to hold for at least one firm, the firms compete instead. 
The discounted profit flow is $\pi_{i}^{\mathrm{P}}(1+1 / r){ }^{2}$ Now consider $R \& D$ at $t=0$. The effect of $R \& D$ is to reduce marginal costs (process innovations):

$$
\mathrm{c}_{\mathrm{i}}=\mathrm{c}-\mathrm{X}_{\mathrm{i}}(\mathrm{i}=1,2)
$$

where $\mathrm{X}_{\mathrm{i}}$ is the effective $R \& D$ or knowledge base. It results from $\mathrm{R} \& \mathrm{D}$ as follows:

$$
X_{i}=x_{i}+\beta x_{j}
$$

where $\beta \in[0,1)$ is the spillover term, and $x_{i}\left(x_{j}\right)$ is firm i's (j's) $R \& D$ level $(i, j=1,2 ; i \neq j)$. Due to (unintentional) leaks, firm j's R\&D spills over to increase firm i's knowledge level (if $\beta>0$ ). To express decreasing returns to $R \& D, R \& D$ costs increase quadratic in $R \& D$ effort, $(\Gamma / 2) x_{i}^{2}$ (D'Aspremont and Jacquemin, 1988). The expected profit at $t=1$ is $\pi_{\mathrm{i}}^{\mathrm{J}}(1+1 / \mathrm{r})$, where $\mathrm{J}=\mathrm{C}$ (collusion) or $\mathrm{J}=\mathrm{P}$ (Cournot competition). The expected profit at $\mathrm{t}=0$ equals $\pi_{\mathrm{i}}^{\mathrm{J}}(1 / \mathrm{r})$ which gives the expected profit functions at period 0 :

$$
\Pi_{\mathrm{i}}=\pi_{\mathrm{i}}^{\mathrm{J}}(1 / \mathrm{r})-(\Gamma / 2) \mathrm{x}_{\mathrm{i}}^{2} \text {, where } \mathrm{i}=1,2,3 \text { and } \mathrm{J}=\mathrm{C}, \mathrm{P} \text {. }
$$

Maximization of this expression leads to the same outcome as maximization of:

$$
\Pi_{\mathrm{i}}=\pi_{\mathrm{i}}^{\mathrm{J}}-(\gamma / 2) \mathrm{x}_{\mathrm{i}}^{2},
$$

2. The model thus assumes that demand for the product is constant, and the product has an infinite life. This assumption does not hold in dynamic industries, such as the IT industries. Note, however, that the interest rate $r$ in the model can be interpreted as a function of the length of the time period, the time preference of the players (or the market interest rate) and a probability that the 'game' (i.e., the product's life) ends in the current period (Rasmusen, 1989, p. 90). Short product life cycles (a high probability of a short life) thus translate in the model to a high interest rate $r$. 
where $\gamma \equiv \mathrm{r} \Gamma$. We compare two cases: merger (firms 1 and 2 cooperate in both stages) and strategic alliance ( 1 and 2 cooperate only in the R\&D stage). The resulting profits depend on four parameters: the demand parameter $b$ (product substitutability), R\&D parameters $\beta$ and $\Gamma$, and the interest rate $r$.

\section{The Third Stage of the Game: The Product Market}

This section considers two cases: in case 1, firms 1, 2 and 3 compete or collude, and case 2: firms 1 and 2 merged into a two-product firm, which competes or colludes with firm 3.

\subsection{Case 1: No Merger}

This subsection explores the product market when the three firms compete. Three sub-cases emerge: case 1.a, where the three firms compete, case 1.b, where the three firms collude, and case 1.c where one firm cheats against the other two, who collude.

\section{Case 1.a: Cournot 3-firm oligopoly}

The profit functions are as in equation (2). The first order condition for profit maximization is:

(8) $\quad a-c_{i}-2 q_{i}-b q_{j}-b q_{k}=0$.

Solve this for the output levels:

(9)

$$
q_{i}^{P 3}=\frac{1}{2} \frac{\left(a-c_{i}\right)(b+2)-b\left(a-c_{j}+a-c_{k}\right)}{2+b-b^{2}} .
$$


The superscript $\mathrm{P}$ for punishment refers to Cournot competition, and the number three refers to the number of independent firms. Substitute these in the profit levels for the optimal profit levels:

$$
\Pi_{i}^{P 3}=\frac{1}{4} \frac{\left(\left(a-c_{i}\right)(b+2)-b\left(a-c_{j}+a-c_{k}\right)\right)^{2}}{(b+1)^{2}(b-2)^{2}}
$$

Case 1.b: three-firm collusion

The firms choose the output levels that maximize their joint profit $\left(\Sigma_{\mathrm{i}}^{3} \pi_{\mathrm{i}}\right)$. The second order condition is satisfied by

(11) $-1 / 2<\mathrm{b}<1$.

This assumption rules out 'close' complements and perfect substitutes. Standard computations give:

$$
q_{i}^{C}=\frac{1}{2} \frac{\left(a-c_{i}\right)(1+b)-b\left(a-c_{j}+a-c_{k}\right)}{1+b-2 b^{2}} .
$$

The superscript omits the number of firms as collusion in case 2 (a duopoly with the merged twoproduct firm) gives the same outcome: it too maximizes $\Sigma_{\mathrm{i}}^{3} \pi_{\mathrm{i}}$. Output levels are certainly positive if $-1 / 2<b \leq 0$. For the sake of the second stage of the game, I note the conditions for positive output levels if $\mathrm{c}_{1}=\mathrm{c}_{2}$ and $0<\mathrm{b}: 0 \leq\left(\mathrm{a}-\mathrm{c}_{3}\right)(1+\mathrm{b})-2 \mathrm{~b}\left(\mathrm{a}-\mathrm{c}_{1}\right)$ and $0 \leq \mathrm{a}-\mathrm{c}_{1}-\mathrm{b}\left(\mathrm{a}-\mathrm{c}_{3}\right)$. Define $\mathrm{d}_{1} \equiv(\mathrm{a}-$ $\left.\mathrm{c}_{1}\right) /\left(\mathrm{a}-\mathrm{c}_{3}\right)$. These conditions amount to 
Substitute these output levels in the profit functions:

$$
\Pi_{i}^{C}=\frac{1}{4}\left(a-c_{i}\right) \frac{\left(a-c_{i}\right)(1+b)-b\left(a-c_{j}+a-c_{k}\right)}{(1+2 b)(1-b)}
$$

Case 1.c: defection by one firm while the others collude

Fim $i$ defects by choosing the output level that maximizes its own profit, while its rivals choose the collusive output levels, $\mathrm{q}_{\mathrm{j}}{ }^{\mathrm{C}}$. Standard computations give:

$$
q_{i}^{D 3}=\frac{2\left(b^{2}-b-1\right)\left(a-c_{i}\right)+b\left(a-c_{k}+a-c_{j}\right)}{4(2 b+1)(b-1)} .
$$

Substitute the output levels, $\mathrm{q}_{\mathrm{i}}{ }^{\mathrm{D} 3}, \mathrm{q}_{\mathrm{j}}{ }^{\mathrm{C}}$ and $\mathrm{q}_{\mathrm{k}}{ }^{\mathrm{C}}$, into the profit function of the defecting firm:

$$
\Pi_{i}^{D 3}=\frac{\left(\left(a-c_{i}\right)\left(2 b^{2}-2 b-2\right)+b\left(a-c_{k}+a-c_{j}\right)\right)^{2}}{16(2 b+1)^{2}(b-1)^{2}} .
$$

\section{Sustainable Collusion if there are three firms}

Equation (3) says that the firms sustain collusion if the interest rate is less than an upper bound, $\max _{\mathrm{i}}^{\mathrm{n}}$ (for firm $i$ and $n$ independent firms). Compute this upper bound for firm $i$ from the optimal profit levels above. For the symmetric case where $\mathrm{c}_{1}=\mathrm{c}_{2}$, and $d_{1}$ is defined above: 


$$
\operatorname{rmax}_{i}^{3}=\frac{\left(A_{1} d_{1}^{2}+A_{2} d_{1}+A_{3}\right)(2 b+1)(b-1)}{\left((2 b-1) d_{1}-1\right)^{2}(b+1)^{2}(b-2)^{2}}(i, j=1,2 ; i \neq j) ;
$$

where $A_{1}=-20-4 b^{2}+8 b, A_{2}=4 b\left(b^{2}+5-2 b\right)$, and $A_{3}=-4(2 b+1)(b-1)$. The same symmetry case gives for firm 3:

$$
\operatorname{rmax}_{3}^{3}=\frac{\left(A_{1} d_{1}^{2}+A_{2} d_{1}+A_{3}\right)(2 b+1)(b-1)}{\left(b-d_{1}\right)^{2}(b+1)^{2}(b-2)^{2}}
$$

where $A_{1}=-8 b^{2}+4 b+4, A_{2}=2 b^{3}+4 b^{2}+6 b-4$, and $A_{3}=-b^{3}-b^{2}-2 b-4$. For the case of full cost symmetry, where $c_{3}=c_{2}=c_{1}$, and consequently $d_{1}=1$, the highest interest rate that sustains collusion is:

$$
\operatorname{rmax}_{i}^{3}=\frac{2 b+1}{(b+1)^{2}}(i=1 . .3)
$$

\subsection{Case 2: Merger by Firms 1 and 2}

This case too consists of three cases.

Case 2.a: The merged firm competes with firm 3

The merged firm maximizes its profit over the products 1 and 2 , which gives the first order conditions: 
(20)

$$
\partial \pi_{12} / \partial q_{i}=0=-2 q_{i}-2 b q_{j}-b q_{3}+a-c_{i}(i, j=1,2 ; i \neq j) .
$$

Firm 3's first order condition is identical to the one in case 1.a. The merged firm's second order condition is satisfied by $1-\sqrt{3}<\mathrm{b}<1+\sqrt{3}$, which includes all cases allowed for by equation (11). Solve the output levels:

$$
q_{i}^{P 2}=\frac{\left(a-c_{i}\right)\left(4-b^{2}\right)-\left(a-c_{j}\right)\left(4 b-b^{2}\right)-\left(a-c_{3}\right)\left(2 b-2 b^{2}\right)}{4\left(b^{2}-2 b-2\right)(b-1)}(i, j=1,2 ; i \neq j)
$$

$$
q_{3}^{P 2}=\frac{\left(a-c_{1}+a-c_{2}\right) b-2(1+b)\left(a-c_{3}\right)}{2\left(b^{2}-2 b-2\right)} .
$$

For the special case where $c_{1}=c_{2}$ (of interest in the second stage of the game), the output level of the merged firm (per product) is positive if $0 \leq 2\left(\mathrm{a}-\mathrm{c}_{1}\right)-\mathrm{b}\left(\mathrm{a}-\mathrm{c}_{3}\right)$, which for positive $b$ is guaranteed by equation (13). Equation (13) also guarantees a positive output level to firm 3 . Substitute the output levels in the profit functions. The outcome for the merged firm is a long expression, which for the symmetry case $c_{1}=c_{2}$ simplifies to:

$$
\pi_{12}^{P 2}=\frac{1}{2}(b+1) \frac{\left(b\left(a-c_{3}\right)-2\left(a-c_{1}\right)\right)^{2}}{\left(b^{2}-2 b-2\right)^{2}} .
$$

The outcome for firm 3 (returning to the general case where costs can be different) is: 
(24)

$$
\pi_{3}^{P 2}=\frac{\left(b\left(a-c_{1}+a-c_{2}\right)-2(1+b)\left(a-c_{3}\right)\right)^{2}}{4\left(b^{2}-2 b-2\right)^{2}}
$$

Case 2.b: Collusion

If both firms collude by maximizing the joint profit $\Sigma_{\mathrm{i}}^{3} \pi_{\mathrm{i}}$, the outcome is the same as in case 1.b.

Case 2.c: one firm cheats against a colluding rival

The aim is to compute the profit of a firm which unilaterally defects against a non-suspecting, colluding, firm. There are two cases to consider. If the merged firm cheats, firm 3 has the output level in case 1.b. Taking this as given, the merged firm chooses the output levels that maximize its own profit level. This gives:

$$
q_{i}^{D 2}=-\frac{\left(a-c_{i}\right)\left(b^{2}+4 b+2\right)+\left(a-c_{j}\right)\left(-3 b^{2}-2 b\right)+\left(a-c_{3}\right)\left(-b^{2}-b\right)}{4\left(2 b^{2}-b-1\right)(b+1)}(i, j=1,2 ; i \neq j) .
$$

Substitute the output levels in the merged firm's profit function, which gives (when $\mathrm{c}_{1}=\mathrm{c}_{2}$ ):

$$
\pi_{12}^{D 2}=\frac{\left(\left(a-c_{1}\right)\left(-2-2 b+2 b^{2}\right)+\left(a-c_{3}\right)\left(b^{2}+b\right)\right)^{2}}{8(b+1)(2 b+1)^{2}(b-1)^{2}}
$$

If, on the other hand, firm 3 unilaterally defects from collusion, it takes the merged firm's collusive output levels as given (see case 1.b), and then maximizes its own profit function. This gives: 
(27)

$$
q_{3}^{D 2}=\frac{\left(a-c_{3}\right)\left(2 b^{2}-2 b-2\right)+b\left(a-c_{1}+a-c_{2}\right)}{4(2 b+1)(b-1)}
$$

Substitute this in firm 3's profit function, along with the merged firm's collusive output levels, to find:

$$
\pi_{3}^{D 2}=\frac{\left(\left(a-c_{3}\right)\left(2 b^{2}-2 b-2\right)+b\left(a-c_{1}+a-c_{2}\right)\right)^{2}}{16(2 b+1)^{2}(b-1)^{2}}
$$

\subsubsection{Sustainable collusion if there are two firms}

Compute the maximum interest rate that allows collusion, defined by the right hand side of equation (3). If the merged firm considers defection, this gives (for $\mathrm{c}_{1}=\mathrm{c}_{2}$ ):

$$
\operatorname{rmax}_{12}^{2}=\frac{4 A B(b+1)(2 b+1)(b-1)}{\left(2 d_{1} b-b-1\right)^{2}\left(b^{2}-2 b-2\right)^{2}}
$$

where $A=d_{1}(b+2)-1-2 b$, and $B=-d_{1}(b+2)-1+b^{2}$. For the full cost symmetry case, where $c_{1}=c_{2}=$ $\mathrm{c}_{3}$, and $\mathrm{d}_{1}=1$, this simplifies to:

$$
\operatorname{rmax}_{12}^{2}=\frac{4(2 b+1)(b+1)\left(b+3-b^{2}\right)}{\left(b^{2}-2 b-2\right)^{2}} .
$$


If fim 3 considers unilateral defection, the maximum interest that sustains its collusion equals (if $\left.\mathrm{c}_{1}=\mathrm{c}_{2}\right)$ :

$$
\operatorname{rmax}_{3}^{2}=\frac{A B(2 b+1)(1-b)}{\left(b-d_{1}\right)^{2}\left(b^{2}-2 b-2\right)^{2}}
$$

where $A=2 d_{1}(1-b)+2+b$, and $B=-2 d_{1}(2 b+1)+2+3 b+b^{2}$. For full cost symmetry this simplifies to:

$$
r m a x_{3}^{2}=\frac{(2 b+1) b(b-4)}{\left(b^{2}-2 b-2\right)^{2}} .
$$

\subsection{Collusion before and after a merger}

The core idea in the merger / collusion discussion (Davidson and Deneckere, 1984) is the

Hypothesis: A merger disrupts collusion if $\min _{12,3}\left(\frac{\pi_{i}^{C}-\pi_{i}^{P 2}}{\pi_{i}^{D 2}-\pi_{i}^{C}}\right)<\min _{1,2,3}\left(\frac{\pi_{i}^{C}-\pi_{i}^{P 3}}{\pi_{i}^{D 3}-\pi_{i}^{C}}\right)$;

that is, a range of interest rates exists, such that at least one fim disrupts collusion after a merger: $\min \left\{\max _{12}{ }^{2}, \operatorname{rmax}_{3}{ }^{2}\right\}<\mathrm{r}$, and all three firms sustain collusion if there is no merger: $\mathrm{r}<$ $\min \left\{\max _{i}^{3}\right\}$. First, consider the special case of full cost symmetry $\left(d_{1}=1\right)$. The expression in equation (32) is negative (for $-1 / 2<b<1$ ). That is, firm 3 defects if the merged firm colludes (as $\max _{3}<0<\mathrm{r}$ ). Thus, if there is a merger, collusion certainly breaks down. If there is no merger, the three fims collude if $r<(2 b+1) /(b+1)^{2}$ (see the previous sub-section). This extends the result 
of Davidson and Deneckere (1984) to heterogeneous goods:

Proposition 1: If products are symmetrically heterogeneous $(-1 / 2<\mathrm{b}<1)$ and costs are symmetric

$$
\left(\mathrm{c}_{1}=\mathrm{c}_{2}=\mathrm{c}_{3}\right) \text {, merger disrupts an existing state of collusion if } r<\frac{2 b+1}{(b+1)^{2}} \text {. }
$$

For the more general case where $c_{1}=c_{2} \neq c_{3}, d_{1}$ is a positive number. The $\max _{i}{ }^{n}$ are functions in

\begin{tabular}{|c|c|c|c|c|c|c|c|c|c|c|c|}
\hline 0 & 0.1 & 0.311 & 0.522 & .73 & .94 & .15 & 36 & .57 & 788 & 2 & \\
\hline-0.499 & 1 & 1 & 1 & 1 & 1 & 1 & 1 & 1 & 1 & 1 & the results of a numerical \\
\hline-0.3326 & 4 & 1 & 1 & 1 & 1 & 1 & 1 & 1 & 2 & 2 & The column \\
\hline-0.1661 & 4 & 2 & 1 & 1 & 1 & 2 & 2 & 2 & 2 & 2 & \\
\hline 0.0003 & 4 & 4 & 1 & 1 & 1 & 2 & 2 & 2 & 4 & 4 & on the left (exclude the 0 \\
\hline 0.1668 & 0 & 4 & 4 & 1 & 1 & 2 & 4 & 4 & 4 & 4 & \\
\hline 0.3332 & 0 & 0 & 4 & 1 & 2 & 2 & 4 & 4 & 4 & 4 & tent \\
\hline 0.4997 & 0 & 0 & 4 & 4 & 2 & 4 & 4 & 0 & 0 & 0 & gives the values of $b$ \\
\hline 0.6661 & 0 & 0 & 0 & 4 & 1 & 4 & 0 & 0 & 0 & 0 & \\
\hline 0.8326 & 0 & 0 & 0 & 0 & 3 & 0 & 0 & 0 & 0 & 0 & 90 \\
\hline 0.999 & 0 & 0 & 0 & 0 & 0 & 0 & 0 & 0 & 0 & 0 & The top row gives the \\
\hline
\end{tabular}

values of $d_{1}$ (from 0.1 to 2 ). The other cells contain the following codes. A ' 0 ' refers to a combination $\left(b, d_{1}\right)$ that is not admissible by equation (13). Collusion is possible if the $\max _{\mathrm{i}}{ }^{\mathrm{n}}$ are positive for all firms (for a given $n$ ). If at least one max is negative, collusion is impossible. A '1' refers to positive values of the $\max _{i}{ }^{n}(i=1 . .3 ; n=2,3)$, such that collusion is possible both before and after merger. A '2' refers to possible collusion before but not after merger. A '3' refers to possible collusion after merger but not before. A '4' refers to impossible collusion either before or after merger.

The table shows that (given $\mathrm{d}_{1}$ ), an increasing $b$ reduces the scope for collusion as case 1 gives way to case 2 and finally case 4 . Proposition 1 refers to case '2' as well as to those subcases of case '1' (not highlighted) where condition (34) holds (while the max's are all positive). These 
cases occur, but so do all the others. This includes the opposite case 3 , the IO folklore where merger stimulates collusion.

In a dynamic context, the situation becomes still more difficult. The merger will lead to different R\&D levels than an alliance, and thus to different marginal cost levels. Not only will $c_{1}$ and $c_{2}$ generally differ from $c_{3}$, but they will differ as to whether firms 1 and 2 merged or formed an alliance.

\section{The Second Stage of the Model: The Choice of R\&D}

Anticipating on the subsequent competition in the product market, firms 1 and 2 choose their R\&D levels. The merger and the alliance choose their R\&D levels in exactly the same way: they choose R\&D levels that maximize firm 1 and 2's joint profits. The merger and alliance have different implications only in the product market, where the merger acts as a single firm and the allied firms act independently. In this model, therefore, mergers and alliances only have a single difference: a merger coordinates both strategic (R\&D) and tactic (output) decisions, whereas an alliance is limited to coordinating a strategic $\mathrm{R} \& \mathrm{D}$ decision. This implies some notable assumptions:

1) There are no transaction costs in realising an alliance or a merger;

2) In both cases the fims choose $R \& D$ levels that maximize their joint profits, hence there is no opportunism (often mentioned as a problem of alliances).

3) There is complete certainty about the profitability of the alliance, merger, and joint $R \& D$ project.

In comparing the merger to the alliance I will first assume that the merger leads to Cournot competition with firm 3, whereas an alliance leads to collusion. After computing the associated outcomes (see the section on results), I check whether they are consistent with this assumption. The solution to the second stage requires two steps. The first is to compute the joint profits of firms 1 and 2 as functions of their marginal costs. The second is to compute the R\&D levels that 
maximize the joint profits.

The first step gives the joint profit of firms 1 and 2. If they remain independent (in an alliance), they collude in the product market with firm 3. Adding the profits from the case 1.b, and rewriting as a function of the marginal costs $\left(\mathrm{c}_{1}, \mathrm{c}_{2}\right)$ gives:

$$
\pi_{12}^{3}=\mathrm{Ac}_{1}^{2}+\mathrm{Bc}_{1}+\mathrm{Cc}_{1} \mathrm{c}_{2}+\mathrm{Dc}_{2}^{2}+\mathrm{Ec}_{2}+\mathrm{F}
$$

where appendix A gives the parameters $A$ through $F$ (which depend on $c_{3}$ and the demand parameters, $a$ and $b$ ). If firms 1 and 2 merge, they compete in the product market with firm 3 . Rewrite the joint profit of case 2.a $\left(\pi_{12}{ }^{\mathrm{P} 2}\right)$ as a function of the marginal costs. This gives the same expression for $\pi_{12}{ }^{2}$ as for $\pi_{12}{ }^{3}$ in equation (33), the only difference being the parameters A through $\mathrm{F}$ (see appendix B). Note that $\mathrm{D}=\mathrm{A}$ and $\mathrm{E}=\mathrm{B}$ due to demand symmetry of firms 1 and 2 . The discounted joint profit of firms 1 and 2 at $\mathrm{t}=0$ equals (with $\mathrm{D}=\mathrm{A}$ and $\mathrm{E}=\mathrm{B}$; see equation 7):

$$
\Pi_{12}{ }^{n}=A\left(c_{1}^{2}+c_{2}^{2}\right)+B\left(c_{1}+c_{2}\right)+C c_{1} c_{2}+F-(\gamma / 2)\left(x_{1}^{2}+x_{2}^{2}\right) \text {, where } c_{i}=c-x_{i}-\beta x_{j}(i, j=1,2) ;
$$

where $n=2$ (merger) or $n=3$ (alliance). The first order conditions of optimality are:

$$
\left(\begin{array}{cc}
2 \cdot C \cdot \beta+2 \cdot A \cdot \beta^{2}-\gamma+2 \cdot A & C+4 \cdot A \cdot \beta+C \cdot \beta^{2} \\
C+4 \cdot A \cdot \beta+C \cdot \beta^{2} & 2 \cdot C \cdot \beta+2 \cdot A \cdot \beta^{2}-\gamma+2 \cdot A
\end{array}\right) \cdot\left(\begin{array}{l}
x 1 \\
x 2
\end{array}\right)=\left[\begin{array}{c}
(1+\beta) \cdot(2 \cdot A \cdot c+B+C \cdot c) \\
(1+\beta) \cdot(2 \cdot A \cdot c+B+C \cdot c)
\end{array}\right]
$$

The second order conditions imply that the determinant of the Hessian matrix should be positive and the leading principal minor (the element in the left upper corner of the matrix) should be negative (Beavis and Dobbs, 1990, p. 36, 25, and 379). That is: 
$2 \cdot \mathrm{C} \cdot \beta+2 \cdot \mathrm{A} \cdot \beta^{2}+2 \cdot \mathrm{A}<\gamma$

and

$$
0<\left(\gamma-\beta 1^{2} \cdot G\right) \cdot\left(\gamma+4 \cdot G-16 \cdot A-4 \cdot \beta 1 \cdot G+16 \cdot A \cdot \beta 1+\beta 1^{2} \cdot G-4 \cdot A \cdot \beta 1^{2}\right)
$$

The second condition uses simplified notation, where $G=2 A+C$; and $\beta_{1}=1+\beta$. The former condition implies that $\gamma$ should be "sufficiently large". If also $\gamma>\mathrm{G} \beta_{1}{ }^{2}$, then the second condition implies that $\gamma+4 \cdot G-16 \cdot A-4 \cdot \beta 1 \cdot G+16 \cdot A \cdot \beta 1+\beta 1^{2} \cdot G-4 \cdot A \cdot \beta 1^{2}$ should be positive. Rewrite this into: $\left(\beta_{1}-2\right)^{2}(4 \mathrm{~A}-\mathrm{G})<\gamma$. Hence "sufficiently large" $\gamma$ satisfy the second order conditions:

(36) Second Order Conditions:

$$
\begin{aligned}
& 2 \mathrm{C} \beta+2 \mathrm{~A} \beta^{2}+2 \mathrm{~A}<\gamma \\
& \left(\beta_{1}-2\right)^{2}(4 \mathrm{~A}-\mathrm{G})<\gamma \\
& \beta_{1}{ }^{2} \mathrm{G}<\gamma .
\end{aligned}
$$

For convenience, write $\delta \equiv \gamma / \beta_{1}{ }^{2}$. The third S.O.C. implies that $\mathrm{G}<\delta$ (for both $\mathrm{G}$ in appendices A and B). See the appendices for the values of $G$ in the case of the merger and the alliance. It can be seen that $G$ for the alliance (appendix A) exceeds the size of $G$ in the merger (appendix $B$ ), with equality if $b=0$. Thus rewrite the third S.O.C. into:

(36c) $\frac{1}{2(2 b+1)(1-b)}<\delta$. 
In terms of interpretation, given that $\delta \equiv \gamma / \beta_{1}{ }^{2}, \gamma=\mathrm{r} \Gamma$ and $\beta_{1}=1+\beta$, this condition means that $r$ should be sufficiently high (or the product life cycle sufficiently short), $\Gamma$ sufficiently large (costly $R \& D$ ), and $\beta$ (R\&D spillover effect) sufficiently small. Solving equation (35) gives the joint profit maximizing choice of R\&D levels:

$$
x_{i}=\beta_{1} \frac{-(B+c G)}{\gamma-G \beta_{1}^{2}}(i=1,2) \text {. }
$$

The $R \& D$ effort is positive if $B+c G \leq 0$ (as $\gamma-G \beta_{1}{ }^{2}$ is positive by the second order condition). Substitute the values for B and G from appendices A (for the alliance) and B (for the merger) to find that this condition holds if: Positive $R \& D$ effort: $0 \leq 2(\mathrm{a}-\mathrm{c})-\mathrm{b}\left(\mathrm{a}-\mathrm{c}_{3}\right)$.

Substitute the optimal R\&D effort into the marginal cost functions, $c_{i}=c-x_{i}-\beta x_{j}$ :

$$
c_{i}=\frac{c \delta+B}{\delta-G}(i=1,2) .
$$

Since $0<\delta-G$ (the third S.O.C.), this expression is positive if $\delta$ is sufficiently large: $-\mathrm{B} / \mathrm{c} \leq \delta$. The conditions $\mathrm{B}+\mathrm{cG} \leq 0$ and $0 \leq \mathrm{c} \delta+\mathrm{B}$ are consistent as $\mathrm{G}<\delta$. Comparing $\mathrm{B}$ in appendices $\mathrm{A}$ and $\mathrm{B}$ shows that both are negative, and -B for the alliance exceeds -B for the merger. Substitute B from appendix A (the alliance) to find: 
(40) Positive marginal cost: $\frac{2 a-b\left(a-c_{3}\right)}{4 c(2 b+1)(1-b)} \leq \delta$.

Since $\mathrm{B}+\mathrm{cG}$ is negative, $\frac{\partial c_{i}}{\partial \delta}=\frac{-(c G+B)}{(\delta-G)^{2}}, \quad$ is positive. Hence, $\delta$ raises marginal cost. The interpretation of $\delta$ is, therefore, the effective costliness of $R \& D$ (including product life cycle and spillover effects). Since $\operatorname{Lim}_{\delta \rightarrow \infty} c_{i}=c$, for infinite $\delta$ the model approaches the static product market model of the previous section. Substitute the optimal $R \& D$ effort and associated marginal cost level in the joint profit function:

$$
\Pi_{12}=\frac{\delta c(2 B+G c)+B^{2}}{\delta-G}+F
$$

\subsection{Results of the Second Stage}

Substitute the product market parameters A through $\mathrm{F}$ from appendices $\mathrm{A}$ and $\mathrm{B}$ into the optimal R\&D effort and marginal cost. Substitute these in turn in the output levels and profit levels to find the results from the second stage of the game. For convenience, write ac for a-c and ac 3 for a-c $c_{3}$. Call the aggregate output level in the market, $\mathrm{Q}\left(=\Sigma_{\mathrm{i}}{ }^{3} \mathrm{q}_{\mathrm{i}}\right)$. If firms 1 and 2 merge, and compete with firm 3 in the product market, the $\mathrm{R} \& \mathrm{D}$, aggregate output and profit levels are: 
$(42)$

$$
\left(x_{1}\right)^{\operatorname{MER}}=(2 \cdot a c-b \cdot a c 3) \cdot \frac{(1+b)}{\left[\beta 1 \cdot\left[\left(b^{4}-4 \cdot b^{3}+8 \cdot b+4\right) \cdot \delta-2 \cdot b-2\right]\right]}
$$

(43)

$$
\mathrm{Q}^{\mathrm{MER}}=\frac{\left[-\left(\mathrm{b}^{2}-2-2 \cdot \mathrm{b}\right) \cdot(-\mathrm{b} \cdot \mathrm{ac}+\mathrm{ac} 3+2 \cdot \mathrm{ac}) \cdot \boldsymbol{\delta}-\mathrm{ac} 3-\mathrm{b} \cdot \mathrm{ac} 3\right]}{\left[\left(\mathrm{b}^{2}-2-2 \cdot \mathrm{b}\right)^{2} \cdot \delta-2-2 \cdot b\right]}
$$

$$
\left(\pi_{12}\right)^{\mathrm{MER}}=\frac{1}{2} \cdot(-2 \cdot \mathrm{ac}+\mathrm{b} \cdot \mathrm{ac} 3)^{2} \cdot \delta \cdot \frac{(\mathrm{b}+1)}{\left[\left(\mathrm{b}^{2}-2 \cdot \mathrm{b}-2\right)^{2} \cdot \delta-2 \cdot b-2\right]}
$$

Because of symmetry, $x_{2}=x_{1}$. If firms 1 and 2 formed an alliance, and collude in the product market with firm 3 , the $R \& D$, aggregate output and profit levels are:

$$
\left(\mathrm{x}_{1}\right)^{\mathrm{ALL}}=\frac{1}{2} \cdot \frac{(-2 \cdot \mathrm{ac}+\mathrm{b} \cdot \mathrm{ac} 3)}{(\beta 1 \cdot(2 \cdot(2 \cdot \mathrm{b}+1) \cdot(\mathrm{b}-1) \cdot \delta+1))}
$$

$$
\mathrm{Q}^{\mathrm{ALL}}=\frac{1}{2} \cdot \frac{(2 \cdot(2 \cdot \mathrm{b}+1) \cdot(\mathrm{b}-1) \cdot(\mathrm{ac} 3+2 \cdot \mathrm{ac}) \cdot \boldsymbol{\delta}+\mathrm{b} \cdot \mathrm{ac} 3+\mathrm{ac} 3)}{((2 \cdot \mathrm{b}+1) \cdot(2 \cdot(2 \cdot \mathrm{b}+1) \cdot(\mathrm{b}-1) \cdot \delta+1))}
$$

$$
\left(\pi_{12}\right)^{\mathrm{ALL}}=\frac{1}{8} \cdot \frac{\left[-8 \cdot a c \cdot(2 \cdot b+1) \cdot(\mathrm{b}-1) \cdot(-\mathrm{b} \cdot \mathrm{ac} 3+\mathrm{ac}) \cdot \delta+\mathrm{b}^{2} \cdot \mathrm{ac} 3^{2}\right]}{\left[\left(4 \cdot \mathrm{b}^{2}-2 \cdot b-2\right) \cdot \delta+1\right] \cdot(2 \cdot b+1) \cdot(\mathrm{b}-1)}
$$

See appendix $\mathrm{C}$ for the output levels. Compare the R\&D levels of the merger and alliance:

$$
\left(\mathrm{x}_{1}\right)^{\mathrm{MER}}-\left(\mathrm{x}_{1}\right)^{\mathrm{ALL}}=\left(\mathrm{ac}-\frac{1}{2} \cdot \mathrm{b} \cdot \mathrm{ac} 3\right) \cdot \delta \cdot \mathrm{b}^{2} \cdot \frac{(\mathrm{b}+2)^{2}}{\beta 1 \cdot\left[\left(\mathrm{b}^{2}-2 \cdot \mathrm{b}-2\right)^{2} \cdot \delta-2 \cdot b-2\right] \cdot(2 \cdot(2 \cdot \mathrm{b}+1) \cdot(\mathrm{b}-1) \cdot \delta+1)}
$$


This give rise to

Proposition 2: The alliance invests a higher $\mathrm{R} \& \mathrm{D}$ effort than the merger (with equality for unrelated products, where $\mathrm{b}=0$ ).

Proof. By equation (38), 2(a-c)-b(a-c $\left.c_{3}\right)$ is positive. Due to $\mathrm{G}<\delta$ for $\mathrm{G}$ in appendices $\mathrm{A}$ and $\mathrm{B}$, it holds that $\left(b^{2}-2 b-2\right)^{2} \delta-2(b+1)$ is positive (see appendix B) and $2(2 b+1)(b-1) \delta+1$ is negative (appendix A). $Q E D$

\section{The First Stage of the Game: Choice of Merger or Alliance}

The firms decide to merge if two conditions hold: 1) the associated profit in equation (44) exceeds the profits of an alliance in (47); and 2) the hypothesis holds that the merger disrupts collusion, while the alliance sustains collusion. The difference of the profit levels, $\Pi^{\mathrm{MER}}-\Pi^{\mathrm{ALL}}$, is

$$
\Pi_{12}^{M E R}-\Pi_{12}^{A L L}=\frac{1}{8} b^{2}\left(a-c_{3}\right)^{2} \frac{A \delta^{2}+B \delta+C}{D E(2 b+1)(b-1)}
$$

where $A=8(2 b+1)(b-1)(-2 b+b d-1+2 d)\left(-b^{2}+b d+2 d+1\right), B=-8-16 b+4 b^{2}+12 b^{3}-b^{4}, C=2(1+b), D=$ $\left(b^{2}-2 b-2\right)^{2} \delta-2(1+b), E=2(2 b+1)(b-1) \delta+1$, and $d \equiv(a-c) /\left(a-c_{3}\right)$. The sign of the difference depends on $d$ (cost efficiency), $b$ (product substitutability) and $\delta$ (the costliness of R\&D). The difference of the aggregate output levels is

$$
Q_{12}^{M E R}-Q_{12}^{A L L}=\frac{1}{2} b\left(a-c_{3}\right) \frac{A \delta^{2}+B \delta+C}{D E(2 b+1)}
$$


where $A=2(b-1)(2 b+1)\left(b^{2}-2 b-2\right)(-b+2 b d-2 d-2), B=2(2 b+1)\left(b^{2}+2\right) d-(b-1)\left(b^{3}+14 b^{2}+22 b+8\right), C=-$ $2(1+b)$, and $\mathrm{D}$ and $\mathrm{E}$ are defined as above.

Because of the complexity, I will numerically simulate the model. The parameters of the simulation are $a c(=\mathrm{a}-\mathrm{c}), a c_{3}\left(=\mathrm{a}-\mathrm{c}_{3}\right), b$ and $\delta$. It holds that $\mathrm{ac}=1$ throughout. The values of $b$ are in $[-0.45,0.9]$. The values of $\delta\left(=\gamma / \beta_{1}{ }^{2}\right)$ are such that equation (36c) holds for all simulated $b$, i.e. $\delta$ in $[3.5,5.25]$ (the upper bound is arbitrary). The variables simulated are: DQ, which is $\mathrm{Q}^{\mathrm{MER}}-\mathrm{Q}^{\mathrm{ALL}}, \mathrm{D}$, which is $\Pi_{12}{ }^{\mathrm{MER}}-\Pi_{12}{ }^{\mathrm{ALL}}$, and the thresholds for the interest rates, $\max _{\mathrm{i}}{ }^{\mathrm{n}}(\mathrm{i}=1,3$; and $n=2,3)$.

All simulations showed that the sign of DQ equals the sign of $b$ : the merger raises the aggregate output level if products are substitutes. If they are complements, an alliance leads to the greater aggregate output level. If products are unrelated $(b=0)$, there is no difference between the merger and alliance (neither in outputs nor in profits).

The table notes if the hypothesis $(\mathrm{H})$, that merger disrupts collusion and an alliance sustains collusion, is confirmed (at least for a range of interest rates). 


\begin{tabular}{|c|c|c|c|}
\hline $\mathrm{ac}_{3}$ & H confirmed & $\mathrm{D \Pi}$ & $\begin{array}{l}\text { Assumption } \\
\text { (pos. output } \\
\text { levels) }\end{array}$ \\
\hline 1 & $\begin{array}{l}-0.3 \leq \mathrm{b} \leq 0.45 \\
\text { [If } 0.6 \leq \mathrm{b} \text {, no collusion possible } \\
\text { either way; } \\
\text { If } \mathrm{b}=-0.45 \text {, alliance disrupts } \\
\text { collusion.] }\end{array}$ & - & $\mathrm{b}<0.9$ \\
\hline 1.4 & $\begin{array}{l}-0.3 \leq b \leq 0 ; \text { and } b=0.45 \text {. } \\
\text { [If } b=-0.45 \text { and } 0.15 \leq b \leq 0.3 \text {, } \\
\text { alliance disrupts collusion; } \\
\text { If } 0.6 \leq b \leq 0.75 \text {, no collusion } \\
\text { possible either way]. }\end{array}$ & $\begin{array}{l}-(-0.3 \leq b \leq 0 \text { plus the area } \\
\text { where } b=0.45 \text { and } 3.5 \leq \delta \\
\quad \leq 3.889) . \\
+(b=0.45 \text { and } 4.083 \leq \delta \leq \\
5.25) .\end{array}$ & $\mathrm{b}<0.71$ \\
\hline 0.95 & $\begin{array}{l}-0.3 \leq b \leq 0.15 \\
{[\text { If } b=-0.45 \text {, alliance disrupts }} \\
\text { collusion; } \\
\text { if } 0.3 \leq b \text {, no collusion possible } \\
\text { either way]. }\end{array}$ & - & $b<0.75$ \\
\hline
\end{tabular}

The table shows that cases exist where firms 1 and 2 either prefer to merge or to form an alliance. Although the alliance sustains collusion with firm 3, this does not necessarily mean that it is more profitable than a merger. In this model, therefore, the firms face a genuine choice between merger and alliance. This complements the analysis in the seminal papers, D'Aspremont and Jacquemin (1988) and De Bondt and Veugelers (1991), where a merger is always more profitable than the alliance. 
Simulations show that the merger is more profitable only if $\mathrm{ac}_{3}$ exceeds ac, that is, if $c_{3}<$ c (see the table, where $\mathrm{ac}_{3}=1.4$ ). That is, only if firms 1 and 2 want to catch up on an initially superior firm 3, they may prefer a merger to an alliance. The reason is that the alliance leads to collusion. Collusion allocates output levels so as to maximize joint profits. If fim 3 has low marginal costs ex post (even taken into account the $\mathrm{R} \& \mathrm{D}$ undertaken by firms 1 and 2), then collusion shifts most of the output to firm 3. In this case, it is better for fims 1 and 2 to merge and to disrupt the collusion. The same holds for a high $\delta$ (see the table, $\mathrm{ac}_{3}=1.4, \mathrm{~b}=0.45$, and compare the outcomes when $3.5 \leq \delta \leq 3.889$ and $4.083 \leq \delta \leq 5.25$ ). If $\delta$ is high, the two firms have low effective R\&D levels, high marginal costs, and low market shares (in collusion). It is then better to disrupt collusion by a merger. The merger is thus a defense mechanism by firms 1 and 2 against a superior (and mature) rival, especially if $R \& D$ is costly. One can hear such defenses, and they may pertain to this situation. The merger is pro-competitive in that it destroys the cartel.

Not all cases bear out the hypothesis that a merger disrupts, and an alliance sustains collusion. If the products are close complements the opposite holds: the merger stimulates collusion and an alliance would disrupt collusion. If products are moderately close substitutes, the table indicates that no collusion is possible whether there is an alliance or a merger. This seems to contradict proposition 1 , where the hypothesis is confirmed for all $b$, as long as there is full cost symmetry. The point is, with endogenous marginal cost levels either the merger or the alliance may show ex post cost symmetry $\left(c_{1}=c_{3}\right)$, but not both at the same time. So proposition 1 never emerges as a special case.

\section{Appraisal}

The model identifies the cases where R\&D alliances may be conducive to collusion (if products are neither close complements nor close substitutes). Compared with a merger, an R\&D alliance 
leads to a higher R\&D effort (proposition 2), but also to a lower aggregate output level (if products are imperfect substitutes, see the table). A merger would disrupt collusion (if products are substitutes).

What does this analysis imply for the IT industry? The IT industry displays two trends. One is convergence: products become closer substitutes. Examples are computer operating systems, telephone lines and cable (substitutes for interactive television), fax machines and computers (where the latter have fax software plus a modem), and television and computers (substitutes for interactive CDs and for on-line services). If products become better substitutes, this translates in the model to increasing levels of $b$. A higher $b$ destroys the possibilities for collusion, as the table above shows (see also the first table). The other trend is shorter product life cycles, which translates in the model to an increasing interest rate $r$ and thereby, increasing $\delta$. For some selected cases (of $b$ and $a-c_{3}$ ), a higher $\delta$ may induce a switch from an alliance to merger, such that collusion breaks down. Both trends, then, tend to destroy cartels.

This analysis sheds some light on the failure of the large European IT firms to establish a cartel (Mytelka, 1995). If an alliance competes against a superior (lower cost) rival, shorter product life cycles tend to lead to a merger and the disruption of collusion. This suggests a close link between the failure to establish a cartel and the acquisitions that occurred among them (which reduced the Big Twelve to a Big Eight). The convergence process in IT industries, shorter product life cycles, and acquisitions in the European IT industry may thus have been conducive to the cartel's demise in the 1990s. 


\section{REFERENCES}

Beavis, B. and Dobbs, I. (1990) Optimization and Stability Theory for Economic Analysis, Cambridge: Cambridge University Press.

Bondt, R. De and R. Veugelers (1991) Strategic Investment with Spillovers, European Journal of Political Economy, 7: 345-366.

Chakrabarti, A., J. Hauschildt, and C. Süverkrüp (1994) Does it Pay to Acquire Technological Firms?, $R \& D$ Management, 24(1): 47-56.

D'Aspremont, C. and A. Jacquemin (1988) Cooperative and Noncooperative R\&D in Duopoly with Spillovers, American Economic Review, 78(5), Dec.: 1133-1137.

Davidson, C. and R. Deneckere (1984) Horizontal Mergers and Collusive Behavior, International Journal of Industrial Organization 2: 117-132.

Hagedoorn, J. and J. Schakenraad (1993) A Comparison of Private and Subsidized R\&D Partnerships in the European Information Technology Industry, Journal of Common Market Studies, 31(3), September 1993: 373-390.

Link, A.N. and L.L. Bauer (1989) Cooperative Research in U.S. Manufacturing, Lexington: Lexington Books.

Mytelka, L.K. (1995) Dancing with Wolves: Global Oligopolies and Strategic Partnerships, in J. Hagedoorn, ed., (1995) Technical Change and the World Economy: Convergence and Divergence in Technology Strategies, Aldershot: Edgar Elgar.

Rasmusen, E. (1990) Games and Information: An Introduction to Game Theory, Oxford: Basil Blackwell.

Veugelers, R. (1993) Een Schets van Belgische Ondernemingen in Allianties, Onderzoeksrapport Nr. 9302, Leuven: Katholieke Universiteit Leuven. 
Appendix A

If the firms form an alliance, they collude in the product market with firm 3 which gives the following parameters:

(A.1) $\quad \mathrm{A}:=\frac{-1}{4} \cdot \frac{(\mathrm{b}+1)}{((2 \cdot \mathrm{b}+1) \cdot(\mathrm{b}-1))}$

(A.2) $\quad \mathrm{B}:=\frac{1}{4} \cdot \frac{(-\mathrm{b} \cdot \mathrm{a}+\mathrm{b} \cdot \mathrm{c} 3+2 \cdot \mathrm{a})}{((2 \cdot \mathrm{b}+1) \cdot(\mathrm{b}-1))}$

(A.3) $\quad \mathrm{C}:=\frac{1}{2} \cdot \frac{\mathrm{b}}{((2 \cdot \mathrm{b}+1) \cdot(\mathrm{b}-1))}$

(A.4) $\quad \mathrm{F}:=\frac{1}{2} \cdot \mathrm{a} \cdot \frac{(-\mathrm{a}+\mathrm{b} \cdot \mathrm{a}-\mathrm{b} \cdot \mathrm{c} 3)}{((2 \cdot \mathrm{b}+1) \cdot(\mathrm{b}-1))}$

(A.5) $\quad \mathrm{G}:=\frac{-1}{(2 \cdot((2 \cdot \mathrm{b}+1) \cdot(\mathrm{b}-1)))}$; where $\mathrm{G} \equiv 2 \mathrm{~A}+\mathrm{C}$.

$\mathrm{D}=\mathrm{A}$ and $\mathrm{E}=\mathrm{B}$ due to demand symmetry of firms 1 and 2.

\section{Appendix B}

If firms 1 and 2 merge and compete in the product market with firm 3, the profit function 
parameters are:

(B.1) $\quad \mathrm{A}:=\frac{1}{8} \cdot \frac{\left(-8 \cdot \mathrm{b}+4 \cdot \mathrm{b}^{2}+4 \cdot \mathrm{b}^{3}-\mathrm{b}^{4}-8\right)}{\left[(\mathrm{b}-1) \cdot\left(\mathrm{b}^{2}-2 \cdot \mathrm{b}-2\right)^{2}\right]}$

(B.2) $\quad \mathrm{B}:=(\mathrm{b}+1) \cdot \frac{(-\mathrm{b} \cdot \mathrm{c} 3+\mathrm{a} \cdot \mathrm{b}-2 \cdot \mathrm{a})}{\left(\mathrm{b}^{2}-2 \cdot \mathrm{b}-2\right)^{2}}$

(B.3) $\quad \mathrm{C}:=\frac{1}{4} \cdot \mathrm{b} \cdot \frac{\left(\mathrm{b}^{3}+4 \cdot \mathrm{b}-4 \cdot \mathrm{b}^{2}+8\right)}{\left[(\mathrm{b}-1) \cdot\left(\mathrm{b}^{2}-2 \cdot \mathrm{b}-2\right)^{2}\right]}$

(B.4) $\quad F:=\frac{1}{2} \cdot(b+1) \cdot \frac{(-b \cdot c 3+a \cdot b-2 \cdot a)^{2}}{\left(b^{2}-2 \cdot b-2\right)^{2}}$

(B.5) $\quad \mathrm{G}:=2 \cdot \frac{(\mathrm{b}+1)}{\left(\mathrm{b}^{2}-2 \cdot \mathrm{b}-2\right)^{2}}$, where $\mathrm{G} \equiv 2 \mathrm{~A}+\mathrm{C}$.

Note that, again, $\mathrm{D}=\mathrm{A}$ and $\mathrm{E}=\mathrm{B}$ due to demand symmetry of firms 1 and 2 . 
Appendix C: Optimal Output Levels

(C.1) $\quad \mathrm{q} 1^{\mathrm{ALL}}:=\frac{1}{4} \cdot \mathrm{ac} 3 \cdot \frac{(4 \cdot(2 \cdot \mathrm{b}+1) \cdot(\mathrm{b}-1) \cdot(\mathrm{b}-\mathrm{d}) \cdot \delta+\mathrm{b})}{((2 \cdot(2 \cdot \mathrm{b}+1) \cdot(\mathrm{b}-1) \cdot \delta+1) \cdot((2 \cdot \mathrm{b}+1) \cdot(\mathrm{b}-1)))}$

where $d \equiv(a-c) /\left(a-c_{3}\right)$. The denominator is positive as $b-1<0$ and $2(2 b+1)(b-1) \delta+1<0$ (from $G<$ $\delta$, with $\mathrm{G}$ for the alliance in appendix A). For a positive output level the numerator should also be positive. A sufficient (but not necessary) condition is that

(C.2) $\mathrm{b}<\mathrm{d}$,

which is more restrictive than assumption (13) that $b<d_{1}=\left(a-c_{1}\right) /\left(a-c_{3}\right)$, as $c_{1} \leq c$ and $d_{1} \geq d$.

(C.3) $\quad \mathrm{q}^{\mathrm{ALL}}:=\frac{1}{2} \cdot \mathrm{ac} 3 \cdot \frac{\left[2 \cdot(2 \cdot \mathrm{b}+1) \cdot(\mathrm{b}-1) \cdot(-\mathrm{b}+2 \cdot \mathrm{b} \cdot \mathrm{d}-1) \cdot \delta-1+\mathrm{b}^{2}-\mathrm{b}\right]}{((2 \cdot(2 \cdot \mathrm{b}+1) \cdot(\mathrm{b}-1) \cdot \delta+1) \cdot((2 \cdot \mathrm{b}+1) \cdot(\mathrm{b}-1)))}$

The numerator is again positive. The denominator should be positive. $-1+b^{2}-b$ is negative on the interval $(-1 / 2,1)$. A necessary (but not sufficient condition) is, given that $b-1<0$, that $-(1+b)+2 b d$ is negative, which is always true for $b \leq 0$, and which otherwise implies that $d<(1+b) /(2 b)$, which follows from equation (13). This condition also implies (for $0<\mathrm{b}$ ) that $\mathrm{b}<1 /(2 \mathrm{~d}-1)$. If, for example, as in the text, $a-c=1$, and $a-c_{3}=0.95$, then $b<0.90$, which excludes close substitutes.

(C.4) Positive $q_{3}^{A L L}: 0<2(2 \mathrm{~b}+1)(\mathrm{b}-1)(2 \mathrm{bd}-(1+\mathrm{b})) \delta-1-\mathrm{b}+\mathrm{b}^{2}$. 
(C.5) $\quad \mathrm{q} 1^{\mathrm{MER}}:=\frac{1}{2} \cdot \delta \cdot\left(\mathrm{b}^{2}-2 \cdot \mathrm{b}-2\right) \cdot \frac{\mathrm{ac} 3 \cdot(\mathrm{b}-2 \cdot \mathrm{d})}{\left[\left(\mathrm{b}^{2}-2 \cdot \mathrm{b}-2\right)^{2} \cdot \delta-2-2 \cdot \mathrm{b}\right]}$

The numerator is positive by the assumption that $\mathrm{G}<\delta$ for the merger (see appendix B). The expression $b^{2}-2 b-2$ is negative on $(-1 / 2,1)$. Due to (C.2), $b\left(a-c_{3}\right)-(a-c)<0$, hence $b-2 d<b-d<0$. So positiveness of the output level is guaranteed.

(C.6) $\quad \mathrm{q} 3^{\mathrm{MER}}:=\mathrm{ac} 3 \cdot \frac{\left[\left(\mathrm{b}^{2}-2 \cdot \mathrm{b}-2\right) \cdot(\mathrm{b} \cdot \mathrm{d}-\mathrm{b}-1) \cdot \delta-\mathrm{b}-1\right]}{\left[\left(\mathrm{b}^{2}-2 \cdot \mathrm{b}-2\right)^{2} \cdot \delta-2 \cdot b-2\right]}$

The numerator is positive. The expression $b^{2}-2 b-2$ is negative. A necessary condition for a positive output level is bd- $(1+b)<0$, which is always true for $b \leq 0$, and otherwise implies that $d<$ $(1+b) / b$, which follows from $\mathrm{a}-\mathrm{c} \leq \mathrm{a}-\mathrm{c}_{1}$ and equation (13). A sufficient condition is:

(C.7) Positive $q_{3}^{M E R}: 0<\left(\mathrm{b}^{2}-2 \mathrm{~b}-2\right)(\mathrm{bd}-(1+\mathrm{b})) \delta-(1+\mathrm{b})$. 